\title{
PENGGUNAAN MEDIA BALOK KUBUS UNTUK MENINGKATKAN KEMAMPUAN MATEMATIK LOGIS ANAK USIA DINI DI TK NASYWA BANDUNG
}

\author{
Lina Oktariani Utami ${ }^{1}$, Indah Sari Utami ${ }^{2}$,Agus Sumitra ${ }^{3}$ \\ TK NASYWA BANDUNG ${ }^{1}$, TK NASYWA BANDUNG ${ }^{2}$, IKIP Siliwangi \\ Bandung ${ }^{3}$ \\ ${ }^{1}$ linaoktarianiutami@gmail.com, 2indahsariutami25@gmail.com, \\ 3delaguspiero@gmail.com
}

Program Studi Pendidikan Guru Pendidikan Anak Usia Dini, Fakultas Ilmu Pendidikan, Institut Keguruan dan Ilmu Pendidikan Siliwangi

\begin{abstract}
This research originated from the problem of low logical mathematical abilities of children and Bandung. This is what underlies the formulation of the problem (1) What is the objective condition of the logical mathematical abilities of early childhood in group A TK Nasywa Bandung? (2) How does the implementation of early childhood logical mathematical ability learning through cubical blocks in group A TK Nasywa Bandung? (3) How to improve the logical mathematical abilities of early childhood after using cuboid beam media in group A Nasywa Bandung Kindergarten? The research objective was to obtain an overview of the use of cubic beam media to improve the logical mathematical abilities of early childhood in group A Nasywa Kindergarten Bandung. The method used in this research is classroom action research (CAR), which is carried out in three cycles using 12 research subjects. This study uses data collection techniques, observation and documentation. Preliminary observations of logical mathematical abilities with an assessment of Not Developing amounted to $73 \%$, Started to Grow by $26 \%$ and Developed Very Good by $1 \%$. However, after using cubical beam media, children's logical mathematical abilities show optimal abilities. Percentage of logical mathematical ability of children of assessment has not developed by $0 \%$, started to develop by $25 \%$ and develops very well by $75 \%$. Based on these data, recommendations given to child educators can be an alternative medium to improve the logical mathematical abilities of early childhood.
\end{abstract}

Keywords: Cube Media, Improving, Logical Mathematical Ability, Early Childhood.

\section{ABSTRAK}

Penelitian ini berawal dari permasalahan tentang kemampuan matematik logis anak yang rendah ditandai dengan kurangnya kemampuan anak dalam menyusun pola dan bilangan menggunakan media balok kubus di TK Nasywa Bandung. Hal ini yang mendasari rumusan masalah (1) Bagaimana kondisi objektif kemampuan matematik logis anak usia dini di kelompok A TK Nasywa Bandung ?(2)Bagaimana pelaksanaan pembelajaran kemampuan matematik logis anak usia dini melalui balok kubus di kelompok ATK Nasywa Bandung? (3) Bagaimana peningkatan kemampuan matematik logis anak usia dini setelah menggunakan media balok kubus di kelompok A TK Nasywa Bandung?. Tujuan penelitian adalah untuk memperoleh gambaran penggunaan media balok kubusuntuk meningkatkan kemampuan matematik logis anak usia dini di kelompok A TK Nasywa Bandung. Metode yang dipakai 


\section{JURNAL CERIA}

ISSN : 2614-6347 (Print) 2614-4107 (Online)

Vol.1 $\mid$ No.4 $\mid$ Juli 2018

yang dalam penelitan ini adalah penelitian tindakan kelas (PTK), yang dilaksanakan tiga siklus dengan menggunakan subjek penelitian sebanyak 12 orang anak. Penelitian ini menggunakan teknik pengumpulan data, observasi dan dokumentasi. Hasil observasi awal kemampuan Matematik logis dengan penilaian Belum Berkembang sejumlah 73\%, Mulai Berkembang sejumlah 26\% dan Berkembang Sangat Baik sejumlah 1\%. Namun setelah menggunakan media balok kubus, kemampuan matematik logis anak menunjukkan kemampuan yang optimal. Persentase kemampuan matematik logis anak penilaian Belum Berkembang sejumlah0\%, Mulai Berkembang sejumlah 25\% dan Berkembang Sangat Baik sejumlah $75 \%$. Berdasarkan data tersebut, rekomendasi yang diberikan untuk pendidik anak usia dapat menjadi media alternatif untuk meningkatkan kemampuan matematik logis anak usia dini.

Kata kunci: Media Balok Kubus, Meningkatkan, Kemampuan Matematik Logis, Anak Usia Dini.

\section{PENDAHULUAN}

Tuntutan pada anak usia prasekolah dalam menguasai konsep dan kemampuan matematika membuat banyak lembaga pendidikan mengajarkan pengetahuan matematika dengan paksaan.

Pada masa keemasan anak, memerlukan pendekatan yang khas untuk dapat memmbantu mengoptimalkan berbagai aspek perkembangan yang mereka miliki (Mulyasa, 2012:121). Adapun maksud dari pendapat tersebut pendidik hendaklah memberikan perhatian dan penanganan yang tepat untuk menangani berbagai minat dan bakat yang dimiliki oleh anak dengan memberikan rangsangan, bimbingan dan bantuan yang tepat dengan tumbuh kembang anak, baik secara fisik maupun psikis.

Pengembangan kemampuan matematik logis anak usia pra sekolah merupakan salah satu aspek perkembangan yang penting untuk meningkatkan cara berfikir anak dalam menyelesaikan masalah agar dapat menjalankan kehidupan sehari-hari sehingga dapat berfikir secara logika.

Untuk itu, pembelajaran pada anak usia pra sekolah berperan penting dalam pembentukan kecerdasan dan sikap belajar pada tahap selanjutnya yaitu pembelajaran menuju sekolah dasar yang masih menjadi bagian dari pembelajaran anak usia dini.

\section{KAJIAN TEORI}

\section{Media Balok Kubus}

Menurut Ahmad Rohani dalam bukunya pengelolaan pembelajaran (2004) mengemukakan bahwa media merupakan segala sesuatu yang dapat ditangkap oleh indra manusia yang berfungsi sebagai perantara, sarana, atau alat untuk proses komunikasi (proses belajar mengajar).

Dalam hal ini kegiatan bermain balok untuk anak usia dini merupakan sarana yang mampu menstimulasi berbagai perkembangan secara menyeluruh.Permainan balok juga dapat meningkatkan jiwa kompetisi matematika terutama dalam berfikir logis dan sistematis.

Melalui kegiatan bermain pola, anak diharapkan mampu menyusun pola secara berurutan, setelah melihat dua hingga tiga pola secara berurutan seperti yang diperlihatkan oleh guru sehingga anak dapat membuat pola sesuai dengan kreatifitasnya.

Melalui kegiatan membilang diharapkan anak dapat memahami konsep bilangan dan lambang bilangan sesuai dengan jumlah benda-benda, dan pengenalan bentuk lambang bilangan.

Bermain dapat dijadikan sebagai sarana untuk menanamkan kecintaan anak terhadap matematika salah satunya melalui permainan balok kubus. Oleh karena itu, angka dapat dikatakan telah menjadi bagian dalam kehidupan sehari-hari. Hal ini menunjukkan bahwa matematika sudah mulai dapat diperkenalkan. 


\section{JURNAL CERIA}

ISSN : 2614-6347 (Print) 2614-4107 (Online)

Vol.1 1 No.4

\section{Kemampuan Matematik Logis}

Yuliani Nurani dalam bukunya metode pengembangan kognitif mengemukakan (2011,h.11.3) bahwa belajar matematika terjadi secara alami seperti pada saat anak bermain, mereka dapat menemukan, menguji serta menerapkan konsep matematika secara alami hampir setiap hari melalui kegiatan yang mereka lakukan.

\subsection{Defenisi Kecerdasan Matematik Logis}

Menurut Suriasumantri (1982, h.191), matematika adalah bahasa yang melambangkan serangkaian makna dari pernyataan yang ingin disampaikan.lambang-lambang matematika bersifat artifisial dan baru memiliki arti setelah sebuah makna diberikan kepadanya.

\subsection{Tujuan Permainan Matematika Anak Usia Dini}

Secara khusus permainan matematika di Taman Kanak-kanak bertujuan agar anak memiliki kemampuan berikut, yaitu:

1) Dapat berfikir logis dan sistematis sejak dini melalui pengamatan terhadap bendabenda kongkrit, gambar ataupun angka yang ada disekitar anak

2) Dapat memahami konsep ruang dan waktu serta dapat memperkirakan kemungkinan urutan suatu peristiwa yang terjadi disekitarnya

3) Dapat berkreatifitas dan berimajinasi dalam menciptakan sesuatu secara spontan Mempelajari matematika membutuhkan begitu banyak hafalan, hitungan atau melacak angkaangka. Dalam hal ini dapat disimpulkan bahwa matematika merupakan salah satu cara dalam melatih anak untuk berfikir dengan cara-cara yang logis dan sistematis.

Berikut ini akan diuraikan tentang berbagai keterampilan yang dibutuhkan anak dalam memahami konsep matematika, yaitu:

1) Patterning (menyusun pola atau gambar) Patterning adalah menyusun rangkaian warna, bagian-bagian, benda-benda dan gerakan-gerakan yang dapat diulang.

2) Pengelompokkan

Mengelompokkan benda-benda kedalam jenis dan ukuran yang sama merupakan kegiatan yang dapat mengasah kemampuan mengamati pada anak tentang persamaan dan perbedaan.

3) Mengurutkan angka

Kegiatan mengurutkan disebut juga dengan kegiatan serialisasi yang merupakan kegiatan mengidentifikasi perbedaan dan mengatur atau mengurutkan benda sesuai dengan karakteristiknya.

4) Problem solving (Memecahkan masalah) Pemecahan masalah adalah kegiatan mempraktekkan matematika dengan cara bekerja dengan menggunakan konsep yang terjadi dimana saja.

\section{Konsep Pendidikan Anak Usia Dini}

Menurut Siti Aisyah dalam bukunya Perkembangan Dan Konsep Dasar

Pengembangan Anak Usia Dini (2014, h 1.3) bahwa batasan tentang anak usia prasekolah antara lain disampaikan oleh NAEYC (National Association For The Education Of Young Children), mengatakan anak usia prasekolah yaitu anak yang berada pada usia 0 sampai 8 tahun, yang terdapat dalam program pendidikan di taman penitipan anak, penitipan anak pada keluarga (Family child care home), pendidikan prasekolah baik swasta maupun negeri, TK, dan SD (NAEYC, 1992).

\section{METODE}

Metode yang dipakai pada penelitian ini menggunakan metode Penelitian Tindakan Kelas.Bentuk penelitian tindakan kelas yang digunakan yaitu peneliti berperan sebagai pengamat dan pemberi tindakan.

Penelitian ini menggunakan PTK Partisipan karena dalam penelitian ini peneliti berperan langsung dalam proses penelitian dari awal hingga akhir. Peneliti melakukan pengamatan sendiri terhadap dirinya sendiri ketika melakukan tindakan.Penelitian tindakan termasuk kedalam penelitian kualitatif.

Menurut Sugiono dalam bukunya Metode Penelitian Kombinasi (mixed Methods) (2014: 294-295), dalam penelitian kualitatif, teori yang dipakai dalam penyusunan proposal penelitian kualitatif masih bersifat sementara dan akan berkembang setelah peneliti memasuki lapangan atau konteks sosial. 


\section{JURNAL CERIA}

ISSN : 2614-6347 (Print) 2614-4107 (Online)

Vol.1 1 No.4 I Iuli 2018

Penelitian dilaksanakan di Taman Kanak-kanak Nasywa Bandung pada kelompok A tahun ajaran 2017/2018. Teknik pengumpulan menggunakan data observasi, wawancara dan studi dokumentasi.

\section{HASIL PENELITIAN}

Anak-anak usia 4-5 tahun (Kelompok A) TK Nasywa memiliki kemampuan yang beraneka ragam. Salah satunya adalah kemampuan matematik logis anak yang merupakan aspek yang sangat penting dan memiliki peranan dalam mengolah informasi dan menyelesaikan masalah untuk dapat menjalankan kehidupan sehari-hari agar dapat berfikir logis dan sistematis.

Berdasarkan hasil wawancara dengan guru di kelompok A, kemampuan matematik logis anak termasuk kategori belum berkembang karena ketika guru melakukan kegiatan evaluasi mengenai materi yang disampaikan hanya sedikit anak yang mampu menyusun pola dan bilangans esuai dengan harapan.

Kemampuan anak dalam hal menyusun pola dan bilangan dengan baik masih belum berkembang sesuai harapan.

Seiring hal tersebut, guru dan peneliti melakukan upaya dengan senantiasa menyiapkan strategi atau metode yang dapat menstimulasi perkembangan matematik logis anak usia dini. Salah satunya yaitu dengan menggunakan media balok kubus yang dapat menjadi sarana untuk dapat mengembangan kemampuan matematik logis anak. Guru senantiasamembimbing anak dalam menggunakan media balok kubus dengan sistematis dan dapat menerapkan berbagai peraturan sehingga pengkondisian pada saat penggunaan media balok kubus dapat dilaksanakan dengan baik.

Sebelum melaksanakan kegiatan, peneliti menyiapkan skenario pembelajaran yang dirancang sebelum penelitian berlangsung.Peneliti melakukan kegiatan konsultasi terhadap guru dan kepala sekolah berkaitan dengan penggunaan media balok kubus dalam mengembangkan kemampuan matematik logis anak.

Pada tahap persiapan peneliti menyediakan balok kubus yang disesuaikan dengan tahapan perkembangan kognitif yaitu kemampuan matematik logis.Balok kubus terdiri dari balok berbentuk kubus dengan angka dan warna disalah satu bagiannya dan disesuaikan dengan intruksi dan tahapan perkembangannya agar sesuai dengan skenario yang telah disiapkan.

Tahap pelaksanaan, guru melakukan kegiatan pengkondisian dengan menyediakan balok kubus yang digunakan anak untuk melakukan kegiatan menyusun pola dan bilangan. Guru menjelaskan pada anak aturan dalam bermain balok kubus. Tiap anak diberikan sepuluh balok kubus yang terdapat angka dan warna disalah satu bagiannya dan diminta untuk menyusun pola dengan mengelompokkan balok sesuai dengan warnanya kemudian anak diminta utuk dapat menyusun sesuai urutan bilangannya yaitu satu sampai sepuluh.Kegiatan selanjutnya adalah anak diberikan tantangan untuk dapat membuat menara sesuai urutan bilangannya tanpa terjatuh.Hal ini dapat menstimulus anak agar mampu berfikir logis dan menyelesaikan masalah.

Tabel 1. Hasil Kemampuan Matematik Logis Anak

\begin{tabular}{|c|c|c|c|c|c|c|c|c|c|c|c|c|c|}
\hline \multirow{3}{*}{ If } & \multirow{3}{*}{ Nama anak } & \multicolumn{9}{|c|}{ Indikator Kemampuan Matematik Logis } & \multirow{2}{*}{\multicolumn{3}{|c|}{ Jumlah kategori }} \\
\hline & & \multicolumn{4}{|c|}{ menyusun pola } & \multicolumn{3}{|c|}{ menyysumb bilangan } & \multicolumn{2}{|c|}{ Mradiullath } & & & \\
\hline & & 1 & 2 & 3 & 4 & 5 & 6 & 7 & 8 & 9 & BB & MB & BSB \\
\hline T. & MRS & 3 & 3 & 3 & 2 & 3 & 3 & 3 & 3 & 3 & - & 1 & 8 \\
\hline 2. & AYL & 3 & 3 & 3 & 3 & 2 & 3 & 3 & 3 & 3 & - & $\mathrm{T}$ & 8 \\
\hline 3. & $\mathrm{~S} F$ & 3 & 2 & 2 & 3 & 2 & 3 & 3 & 3 & 3 & - & 3 & 6 \\
\hline 4. & ARN & 3 & 2 & 3 & 3 & 3 & 3 & 3 & 3 & 3 & - & 1 & 8 \\
\hline 5. & KYL & 3 & 3 & 3 & 2 & 3 & 3 & 3 & 3 & 3 & - & 1 & 8 \\
\hline 6. & ARS & 2 & 2 & 3 & 3 & 2 & 3 & 3 & 2 & 3 & - & 4 & 5 \\
\hline$T$. & ARG & 3 & 2 & 2 & 3 & 3 & 3 & 3 & 3 & 3 & - & 2 & 7 \\
\hline 8. & ASH & 3 & 2 & 2 & 3 & 2 & 3 & 3 & 3 & 3 & - & 3 & 6 \\
\hline 9. & AUL & 2 & 3 & 3 & 3 & 2 & 3 & 3 & 3 & 3 & - & 2 & 7 \\
\hline III & $\mathrm{Z} D$ & 3 & 3 & 3 & 3 & 3 & 3 & 3 & 3 & 3 & - & - & 9 \\
\hline $\mathbb{1}$. & FDL & 2 & 2 & 2 & 3 & 2 & 3 & 3 & 2 & 3 & - & 5 & 4 \\
\hline II & NDY & 2 & 3 & 2 & 3 & 3 & 2 & 3 & 2 & 3 & - & 4 & 5 \\
\hline t & & 0 & & & & & $\mathrm{a}$ & & & $T$ & 0 & 27 & 81 \\
\hline $\mathrm{P}$ & $\mathrm{e}$ & & & e & $\mathrm{n}$ & $\mathrm{t}$ & z & & & $\mathrm{e}$ & $0 \%$ & $25 \%$ & $75 \%$ \\
\hline
\end{tabular}

Keterangan indikator:

1. Anak mampu mengklasifikasikan benda berdasarkan warna dan ukuran

2. Anak mampu mengurutkan pola-pola sederhana 


\section{JURNAL CERIA}

ISSN : 2614-6347 (Print) 2614-4107 (Online)

Vol.1 I No.4 ل Juli 2018

3. Anak mampu membilang angka 1 sampai 10

4. Anak mampu menyusun angka membentuk menara 1 sampai 10

5. Anak mampu memfokuskan perhatiannya saat bermain balok kubus

6. Anak mampu menyusun menara 5 sampai 10 balok kubus tanpa terjatuh

7. Anak mampu melaksanakan dua sampai tiga perintah secara sederhana.

Keterangan kategori:

BB : Belum berkembang (1)

MB : Mulai berkembang (2)

BSB : Berkembang sangat baik (3)

Adapun secara keseluruhan kemampuan matematik logis anak dapat dilihat pada grafik di bawah ini:

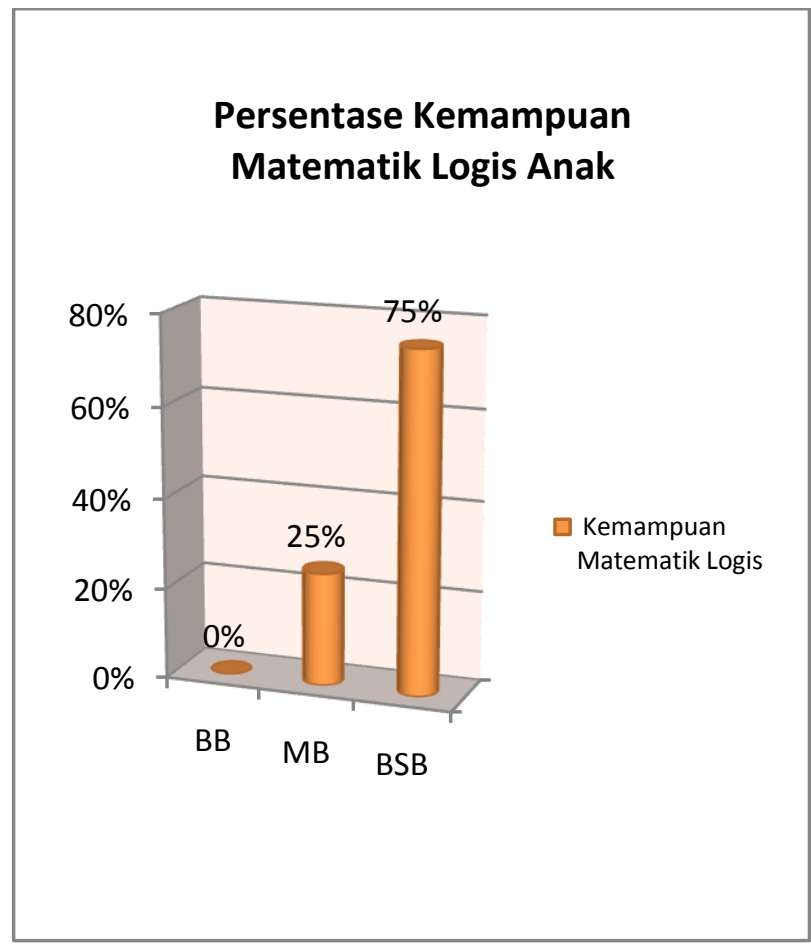

Grafik 1.

Persentase Kemampuan Matematik Logis Anak

\begin{tabular}{|l|l|l|l|l|l|}
\hline Rikegun & Pra Siklus & Siklus 1 & Siklus 2 & Siklus 3 & $\begin{array}{l}\text { Kenaikan atau } \\
\text { penurunan }\end{array}$ \\
\hline
\end{tabular}

\begin{tabular}{|c|c|c|c|c|c|}
\hline BB & $73 \%$ & $37,03 \%$ & $12 \%$ & $0 \%$ & $-73 \%$ \\
\hline$\overline{M B}$ & $26 \%$ & $41,67 \%$ & $38 \%$ & $25 \%$ & $-\quad 1 \%$ \\
\hline BSB & $1 \%$ & $21,30 \%$ & $50 \%$ & $75 \%$ & $+74 \%$ \\
\hline
\end{tabular}

Tabel 2.

Perbandingan Persentase kemampuan matematik logis Anak Pra Siklus dan Setelah Siklus

\section{KESIMPULAN}

Pada dasarnya setiap anak dianugerahi kecerdasan matematiklogis yang didefinisikan sebagai kemampuan penalaran ilmiah, perhitungan secara matematis, berpikir logis, penalaran induktif/deduktif, dan ketajaman polapola abstrak serta hubungan-hubungan.Dapat diartikan juga sebagai kemampuan menyelesaikan masalah yang berkaitan dengan kebutuhan matematika sebagai solusinya.

Prinsip pembelajaran matematika merupakan hal penting yang harus dilaksanakan guru dalam setiap kegiatan pembelajaran matematika agar penyampaian matematika sesuai dengan karakteristik perkembangan anak.

\section{DAFTAR PUSTAKA}

Aisyah, Siti. 2014. Perkembangan Dan Konsep Dasar Pengembangan Anak Usia Dini. Penerbit Universitas Terbuka. Banten. 1.3p

Nurani, Yuliani et al. 2011. Metode Pengembangan Kognitif. Penerbit Universitas Terbuka. Jakarta. 11.3p

Rohani, Ahmad. 2004. Pengelolaan Pengajaran. Rineka Cipta. Bandung Sugiono.(2014). Metode Penelitian Kombinasi (mixed Methods).Alfabeta. Bandung. 294$295 \mathrm{p}$

Suriasumantri, Jujun. (1982). Filsafat Ilmu.

Pustaka Sinar Harapan. Jakarta. 191p 